Bonatesta, F, Chiappetta, E and La Rocca, A

Part-load particulate matter from a GDI engine and the connection with combustion characteristics

Bonatesta, F, Chiappetta, E and La Rocca, A (2014) Part-load particulate matter from a GDI engine and the connection with combustion characteristics. Applied Energy, 124. pp. 366-376.

doi: 10.1016/j.apenergy.2014.03.030

This version is available: https://radar.brookes.ac.uk/radar/items/8d6e1eb0-7677-4b91-ae74-3056d63208d8/1/

Available on RADAR: July 2016

Copyright $(C$ and Moral Rights are retained by the author(s) and/ or other copyright owners. A copy can be downloaded for personal non-commercial research or study, without prior permission or charge. This item cannot be reproduced or quoted extensively from without first obtaining permission in writing from the copyright holder(s). The content must not be changed in any way or sold commercially in any format or medium without the formal permission of the copyright holders.

This document is the post print version of the journal article. Some differences between the published version and this version may remain and you are advised to consult the published version if you wish to cite from it. 


\title{
Part-Load Particulate Matter from a GDI Engine and the Connection with Combustion Characteristics
}

\author{
F. Bonatesta ${ }^{a}$, E. Chiappetta ${ }^{a}$, A. La Rocca ${ }^{b}$ \\ ${ }^{a}$ Department of Mechanical Engineering and Mathematical Sciences, Oxford Brookes University, Wheatley Campus, Oxford, \\ OX33 1HX, United Kingdom \\ ${ }^{b}$ Department of Mechanical, Materials and Manufacturing Engineering, University of Nottingham, University Park, Nottingham, \\ NG7 2RD, United Kingdom
}

\begin{abstract}
The Gasoline Direct Injection engines are an important source of ultra-fine particulate matter. Significant research effort is still required as improved understanding of soot formation is critical in considering further development or adoption of new technologies. Experimental measurements of engine-out soot emissions have been taken from a modern Euro IV GDI engine at part-load operating conditions. The engine speed and torque were varied in the range 1600 to $3700 \mathrm{rev} / \mathrm{min}$, and 30 to $120 \mathrm{Nm}$, respectively. The engine was invariably operated in stoichiometric and homogeneous combustion mode, with fuel injection early in the intake stroke. The results indicate that for engine load in excess of 3 bar Brake Mean Effective Pressure, due to incomplete gasphase mixture preparation, a consistent linear correlation establishes between combustion duration and soot particle number. On average, a six-fold increase in number concentration between 1.0 and $6.0 \times 10^{6}$ particle per cc, arises from shortening the rapid duration of 4 crank angle degrees. For engine speed in excess of $3000 \mathrm{rev} / \mathrm{min}$ and load in excess of 7 bar BMEP, this correlation appears to be superseded by the effects of spray-to-piston impingement and consequent pool-fire. Three main areas of concern have been identified within the part-load running envelope: 1 . the higher load-lower speed range and 2. the mid load-mid speed range, where high nucleation rates induce copious increases of engine-out soot mass; 3 . the upper part-load range where, most likely as a result of spray impingement, high levels of soot concentration (up to 10 million particles per cc) are emitted with very small size $(23-40 \mathrm{~nm})$.
\end{abstract}

\section{Introduction}

Compared to more conventional Port-Fuel Injection (PFI) engines, Gasoline Direct Injection (GDI) engines show a significant 5 to $15 \%$ improvement in fuel economy [1], especially because of higher volumetric efficiency and higher knock resistance, which allow the use of generally higher compression ratios with sizeable benefits in thermal efficiency and specific power output. In spite of this, GDI engines are an important source of environmental pollution because of their fine and ultrafine Particulate Matter (PM) emissions. Sizeable research effort has been devoted in the last two decades to investigate the causes of soot emission from this comparatively young technology. Recent medical research work, showing that aerosol particles in the ultrafine size range (diameters of less than $100 \mathrm{~nm}$ ) cause adverse health effects [2-6], continue to give relevance and impetus to GDI research. Pulmonary inflammation, asthma and cardiovascular conditions are some of problems associated with the deposition of soot in the respiratory tracts. Health risks generally increase with decreasing particle size and increasing concentration. A recent, large, European study associate an $18 \%$ increased risk of lung cancer to a $5 \times 10^{-6} \mu \mathrm{g} / \mathrm{cc}$ increase of $\mathrm{PM}_{2.5}$ in atmospheric air [7]. Compared to diesel engines without particulate filter (non-DPF), GDI engines produce smaller particles in greater number [8] and hence represent an increased level of threat. Gaining an improved understanding of the soot formation process, and its connection with combustion, is of paramount importance as this would enable further developments in engine design and combustion control strategies to reduce PM emissions [9, 10]. Limiting the exhaust gas soot number concentration in GDI engines is one of the main objectives of new proposed emission regulations across the globe [9].

In GDI engines, the process of fuel vaporisation and gas-phase mixing remains essentially incomplete [8], even when early fuel injections are used to enable an homogeneous combustion 
mode $[11,12]$. This leads to the establishment of sub-stoichiometric mixture-pockets, which are an important source of soot formation. A second source is from fuel-spray impingement into cylinder liner and piston crown, and resulting pool-fire [9, 13, 14]. As suggested by Maricq et al. [15], another source of PM formation, especially when GDI engines operate in stratified mode, is attributable to incompletely volatilized fuel droplets, as the unburned gas is swept across by the incoming flame front. The particle number concentration emitted by GDI engines are generally higher than conventional PFI engines and Diesel engines equipped with Particulate Filter (DPF). This trend was shown in a study by Braisher et al. [16], which compares four types of modern engines. The reported total soot particle numbers over the length of the New European Drive Cycle (NEDC) are as follows: $6.7 \times 10^{14}$ for Non-DPF Diesel engine; $6.8 \times 10^{13}$ for GDI engine, $6.0 \times 10^{12}$ for $\mathrm{PFI}$ engine and $1.3 \times 10^{12}$ for DPF Diesel engine. A recent paper by Choi et al. [10] compares wallguided to more recent GDI combustion systems, such as spray-guided and air-guided. The paper reviews the technologies and the potential mechanisms of soot formation in each of them, on the basis of experimental measurements of exhaust soot. Remarkably, "none of these [technologies] were able to satisfy the proposed particle number regulations for Euro 6 standards" [10]. Improved combustion chamber design and injection strategies appear highly necessary at present to reduce particulate matter emissions.

\subsection{Soot Formation Mechanism and Exhaust Measurements}

The phenomenon of soot formation is typically described in terms of three steps: nucleation, growth and oxidation [17]. The process occurs under fuel-rich conditions, in both premixed and non-premixed flames, where the local equivalent ratio is more than one. The nucleation process takes place under high temperature conditions, between 1000 and $2800 \mathrm{~K}$, with unburned hydrocarbons, in particular acetylene and polycyclic aromatics hydrocarbons (PAH), being pyrolyzed and oxidized. The condensation reactions of these gas-phase species lead to a large number of primary soot particles with diameter lower than $2 \mathrm{~nm}$ and insignificant soot loading. Surface growth, coagulation and aggregation represent the particles growth. During surface growth, concentric shells on nuclei and spherules are formed by deposition of hydrocarbon intermediate gas-phase species on particles surface. By means of coagulation the particles collide and merge reducing their total number. After formation, the collision between particles leads to clusters or chain-like aggregates (secondary particles), with a consequent size increase (equivalent diameter of 100 to $900 \mathrm{~nm}$ ). In the overall soot formations process, the precursors, the nuclei and particles can be oxidized if in contact with oxidizing species as $\mathrm{O}_{2}, \mathrm{O}, \mathrm{OH}, \mathrm{CO}_{2}, \mathrm{H}_{2} \mathrm{O}$ at the right conditions. The exhaust soot emissions depend on the balance between formation and burnout processes [18]. The vast majority of formed soot is completely oxidised within the combustion chamber $[9,13]$.

One of the most common instruments to measure size-resolved soot number concentration distribution in exhaust gas samples is the Differential Mobility Spectrometer (DMS). The DMS-500 system by Cambustion, used in this work, is a real-time instrument which classifies particles on the basis of their electrical mobility equivalent diameter [19-22]. Electrical mobility is measured within the classifier column in which a central high-voltage rod deflects the charged particles towards 22 grounded electrometer rings via electrical repulsion. Size discrimination is obtained by separating the particles on the basis of their aerodynamic drag-charge ratio, ultimately dependent on the particle diameter. The range of detection is between 5 and $1000 \mathrm{~nm}$, and the response time 200 ms. Typically, the particles are said to be in nucleation mode when their size is smaller than $50 \mathrm{~nm}$; and in accumulation mode when size ranges between 50 and $1000 \mathrm{~nm}$ [21]. Another system based on electrical mobility theory is the Differential Mobility Analyser (DMA), usually coupled with a Condensation Particle Counter (CPC) that measures particles number concentration by optical detection [23]. The combination of DMA and CPC is configured as a Scanning Mobility Particle Sizer (SMPS) [24]. The Electrostatic Low Pressure Impactor (ELPI) is based on inertia principles $[25,26]$. Price et al. [20] found a qualitative agreement between all instruments by measuring PM emissions from a passenger vehicle equipped with a GDI engine. Importantly, the agreement was stronger for PM mass measurements than for PM number concentration.

Maricq et al. [15] thoroughly examine the connection between soot formation and engine variables, which are changed in isolation enabling the identification of potential pathways to reducing 
particulate emissions. At fixed speed and load, stratified combustion mode produces in general up to two orders of magnitude more particles than homogeneous mode. In both modes, PM number density increases as the ignition timing is advanced, while the peak of the size-resolved distribution shifts towards bigger particle diameters. In homogeneous mode, an ignition timing of $21 \mathrm{CA}$ deg BTDC produced peak number density of $6.0 \times 10^{5} \mathrm{~N} / \mathrm{cc}$, located at $70 \mathrm{~nm}$. Advancing the ignition timing to 40 CA deg BTDC raises the peak number density to $2.0 \times 10^{6} \mathrm{~N} / \mathrm{cc}$, and shifts the peak location to $85 \mathrm{~nm}$. Increased nucleation rates are associated with greater peak combustion temperature, as the ignition timing is advanced earlier in the compression stroke. On one hand, higher particle concentration in the burned gases leads to higher coagulation rate; on the other hand, greater ignition advance causes lower exhaust gas temperature, hence lower post-flame oxidation. Both mechanisms would enable the emission of generally bigger particles when the ignition timing is advanced [27].

Graskow et al. [28] investigate the exhaust soot characterisation using a vehicle equipped with GDI engine. In theoretically-homogeneous mode, at a vehicle speed of $90 \mathrm{~km} / \mathrm{h}$, the total soot number density was $9.3 \times 10^{7} \mathrm{~N} / \mathrm{cc}$ and the Geometrical Mean Diameter (GMD) was $88 \mathrm{~nm}$. In stratified mode, an increase in vehicle speed was associated to increased soot nucleation rate. The total number density increased in the range 1.14 to $2.8 \times 10^{8} \mathrm{~N} / \mathrm{cc}$, and the GMD increased between 35 to $81 \mathrm{~nm}$.

134

135

136

137

138

139

140

141

142

143

144

145

146

147

148

149

150

151

152

153

154

155

156

157

158

159

160

161

162

163

164

165

166

167

168

169

170

Price et al. [29] investigate soot exhaust emissions from a spray-guided GDI engine using toluene as fuel. In line with previous results, they show that increasing ignition advance between 30 and 45 CA degrees BTDC produces an order of magnitude increase in peak soot number density, between $3 \times 10^{5}$ and $3.1 \times 10^{6} \mathrm{~N} / \mathrm{cc}$, with a slight downwards trend in particle size at peak values, which changed between 25 and $18 \mathrm{~nm}$. Soot particles size distribution shows a peak at about 25 $\mathrm{nm}$ independently of Start Of Injection (SOI), whereas the peak number density increases from $2.5 \times 10^{5}$ to $2.4 \times 10^{6} \mathrm{~N} / \mathrm{cc}$ when SOI is shifted from 300 to $200 \mathrm{CA}$ deg BTDC. Spray-guided combustion forms soot mostly in the nucleation mode range, with typical GMD of $30 \mathrm{~nm}$. Over the same operating range, a second experimental GDI engine using wall-guide combustion system emitted on average bigger soot particles, in much greater quantity (up to two orders of magnitude).

Farron et al. [30] report a comprehensive investigation on the influence of engine operating variables on PM exhaust emissions, using a GDI engine and SMPS measurements. At low engine load, they found the lowest particle number density $\left(1.6 \times 10^{5} \mathrm{~N} / \mathrm{cc}\right.$ distribution peak) for End of Injection (EOI) of $280^{\circ}$ BTDC and an increase for both earlier EOI of $330^{\circ} \mathrm{BTDC}\left(1,2 \times 10^{7} \mathrm{~N} / \mathrm{cc}\right)$ and later EOI of $100^{\circ}$ BTDC $\left(1,15 \times 10^{7} \mathrm{~N} / \mathrm{cc}\right)$. The corresponding particle sizes at peak number density were $30 \mathrm{~nm}, 150 \mathrm{~nm}$ and $80 \mathrm{~nm}$, respectively. Increasing engine load led to higher PM mass due to increased fuelling quantity. Doubling the mass of fuel injected per cylinder from 11 to $21 \mathrm{mg}$, produced almost an order of magnitude increase in peak number density, between $1.6 \times 10^{5}$ and $1.2 \times 10^{6} \mathrm{~N} / \mathrm{cc}$. As the engine load was increased, the particle size of peak N/cc increased between 30 and $60 \mathrm{~nm}$. At low engine load, increased ignition retard induced a reduction of PM, both in size and number density. A similar effect was obtained by increasing the fuel pressure, on account of smaller fuel droplets size.

Whitaker et al. [31] investigate various gasoline direct injection strategies to reduce soot particle number. In cold start conditions, a 4-stage split, high-pressure, reduced-duration injection reduces the peak soot number density from $1.8 \times 10^{8}$ to $3.0 \times 10^{7} \mathrm{~N} / \mathrm{cc}$. Similar strategies are used to reduce soot emissions at steady-state, fully-warm engine conditions.

Barone et al. [24] use SMPS to characterise exhaust soot from a 2.0 litre GDI engine operated in theoretically-homogeneous mode, and Transmission Electron Microscopy (TEM) to investigate the morphology of particles and aggregates. An early fuel injection strategy (Start Of Injection, SOI of 320 CA deg BTDC) produced total particle number density N/cc of $1,7 \times 10^{7}$, with a Geometric Mean Diameter (GMD) of $66 \mathrm{~nm}$. Morphology studies showed single solid spheres with a sub-25 nm diameter, nano-particle aggregates ranging between 8 and $52 \mathrm{~nm}$ and liquid droplets with size between 40 and $400 \mathrm{~nm}$. Most aggregates had fractal-like morphology similar to diesel soot. A more retarded injection strategy (SOI of 280 CA deg BTDC) lowered the total number density of 
about one order of magnitude to $1,2 \times 10^{6} \mathrm{~N} / \mathrm{cc}$, with a GMD of $48 \mathrm{~nm}$. The particle morphology was similar to that of early injection, but the presence of liquid droplets was negligible. Similar results on PM characterisation, and its variation with injection timing, have been reported by Sabathil et al [32]. The reduction in PM number density experienced at later injection timings may be explained with the reduced incidence of the fuel-spray impingement, hence reduced wall-wetting.

Pei et al. [33], in their recent GDI engine investigation, emphasise the reliance of PM emissions on engine operating parameters, at part-load conditions. Owing to the inherent incomplete gas-phase mixing, the measured soot number density increases with decreasing Air Fuel Ratio (AFR), retarded SOI and advanced ignition timing. When AFR varies between 18 and 11 , the total range of variation of soot number concentration is between $5.1 \times 10^{7}$ and $5.6 \times 10^{8} \mathrm{~N} / \mathrm{cc}$. Correspondingly, the soot GMD increases from 9 to $30 \mathrm{~nm}$. For all parametric studies, Pei et al. [33] attempt identifying a relationship between PM emissions and combustion characteristics such as combustion temperature and heat release rate.

This paper analyses experimental measurements of engine-out soot emissions and combustion characteristics from a wall-guided GDI engine operated in stoichiometric and homogeneous mode, at part-load running conditions. A survey of relevant literature shows compelling evidence that soot formation in GDI engines is triggered by incomplete air-fuel mixture preparation $[9,10,13,15,24$, $29,30,32,34]$. As variable amounts of soot are emitted as a result of different engine operating variables, this evidence suggests the existence of a relationship between engine burning characteristics and the process of soot formation. The primary aim of the present work has been to explore the correlation between soot number density and combustion characteristics, with specific emphasis given to flame propagation duration and unburned gas temperature.

\section{METHODOLOGY}

\subsection{Engine Testing and Data Acquisition}

Engine testing was carried out using a 1.6 litre, turbo-charged and intercooled, Euro IV, Direct Injection Spark Ignition (DISI), gasoline engine with no modifications. The engine technical specifications are given in Table 1. The engine was installed on a laboratory test bed and controlled by a Schenck W150 eddy-current dynamometer, via a CP Engineering CADET engine control and data acquisition system. Fuel consumption was measured via a CP Engineering FMS400 gravimetric system. Engine testing was carried out under steady-state, fully-warm operating conditions crossing a large portion of the part-load running envelope. Engine speed was varied in the range 1600 to $3700 \mathrm{rev} / \mathrm{min}$, in steps of $700 \mathrm{rev} / \mathrm{min}$; torque was varied in the range 30 to 120 $\mathrm{Nm}$, in steps of $30 \mathrm{Nm}$. A total of 16 operating conditions were investigated and the tests were repeated three times to ensure consistency and repeatability. The spark timing was controlled via the manufacturer ECU, optimised for best thermal efficiency and minimal fuel consumption. The fuel injection strategy was also controlled via the ECU, ensuring a theoretically homogeneous air/fuel mixture with an equivalent ratio of 1.0 at the conditions tested. In the wall-guided DISI combustion system used here, the fuel is injected into the combustion chamber by a side-mounted injector. The mixture is then 'guided' towards the spark-plug region by the charge motion (reverse tumble) and a spoon-shaped piston crown. The delivery of fuel is via a common-rail direct injection system; injection pressure is regulated via the ECU as a function of load and speed, with a maximum value of 120 bar. The fuel used for testing was pump-grade, $95 \mathrm{RON}$ unleaded gasoline with a stoichiometric AFR of 14.4. A Kistler piezo-electric, spark-plug mounted, pressure transducer was installed in one cylinder to acquire in-cylinder pressure variation. Batches of 100 consecutive pressure cycles were acquired via an AVL Indicom acquisition system to evaluate the ensemble-averaged pressure trace, and the combustion evolution in terms of Mass Fraction Burned (MFB) profile. A schematic of the engine rig experimental setup is presented in figure 1.

\section{Figure 1}

\section{Table 1}




\subsection{Engine-Out Soot Measurements}

Parallel measurements of exhaust gas soot content and size distribution were performed using the Cambustion DMS-500 system. The sampling point for engine-out gas stream was fitted into the exhaust manifold, close to the exhaust port of the cylinder were pressure measurements were taken. The gas sample was passed through a capillary tube into a heated switch valve at a constant temperature of $190^{\circ} \mathrm{C}$. A heated sample line maintained at $58^{\circ} \mathrm{C}$ connected the switch unit to the PM measurement unit. A scroll vacuum pump was used to draw the sample at a constant mass flow rate. PM measurements were consistently carried out using a primary dilution ratio of 5 and a secondary dilution ratio of 25 , respectively. At each steady-state condition, the exhaust stream was sampled for 10 minutes. The data was time-average via the manufacturer software to yield the size-resolved soot number density distribution. The particle mass was calculated by taking a limiting assumption that the particles are spherical and have a density of $1800 \mathrm{~kg} / \mathrm{m}^{3}$. As for the in-cylinder pressure measurements and cycle-resolved engine data, also the engine-out soot measurements were repeated three times. Following Farron [30], the repetitions were taken not only during the same testing day, but also during different days. Typical repetitions of time-averaged, size-resolved number density distributions are presented in figure 2. Although some low variability is expected as the running conditions can never be exactly reproduced [30], the low combustion variability at the conditions investigated enable PM measurements with acceptable repeatability. Similarly to Chen et al. [34], the data referring to particle size below $10 \mathrm{~nm}$ were excluded from the analysis due to increased variance in that range.

\section{Figure 2}

\subsection{Mass Fraction Burned Calculation}

The following correlation, derived from the original methodology by Rassweiler and Withrow [35, $36]$, has been used to evaluate the Mass Fraction Burned, $x_{M F B}$, as a function of crank angle:

$\left[x_{M F B}\right]_{\vartheta}=\frac{\left[m_{b}\right]_{\vartheta}}{m_{f c}} \approx \sum_{\vartheta_{S T}}^{\vartheta} \Delta P_{c} / \sum_{\vartheta_{S T}}^{E O C} \Delta P_{c}$

Here, $\left[m_{b}\right]_{\vartheta}$ is the mass actually burned at any location $\vartheta$ after combustion initiates (ignition timing) and $m_{f_{c}}$ is the mass of fresh charge, including air and fuel, trapped inside the engine cylinder at IVC. $\Delta P_{C}$ is the pressure rise due to combustion in one CA step, calculated as difference between the total experimental pressure rise, and the one due only to volume variation. EOC indicates the CA location of End Of Combustion, corresponding to $100 \%$ MFB. In the present work, two different values of the polytropic index are used to model the pressure variation due to volume change; one for the compression and one for the power stroke. The polytropic compression index is calculated as the negative of the slope of the experimental $[\log V, \log P]$ diagram over 30 consecutive points before spark timing, and maintained unvaried up to TDC. While the sensitivity of the MFB profile to the compression index is relatively low, the selection of the expansion index is more important. The expansion index is estimated with an iterative procedure where, starting from a reference value (e.g. 1.3), the index is progressively adjusted together with the EOC. The iterations continue until the MFB curve acquires a reasonable S-shape, which meets the requirement of zero combustion-pressure condition, i.e. the curve remains steadily at $100 \%$ after EOC. In this work the combustion process is supposed to terminate when $\Delta P_{C}$ becomes a negligible fraction (within $0.2 \%$ ) of the total pressure increment, for 4 CA-steps consecutively. The uncertainties and accuracy associated to this methodology are more comprehensively discussed in $[35,36]$.

Two common combustion duration indicators are calculated from the MFB curve, Flame Development Angle (FDA) and Rapid Burning Angle (RBA). FDA in calculated as the interval between spark timing and $10 \%$ MFB. RBA is calculated as the interval between $10 \%$ and $90 \%$ MFB. The selection of $90 \%$ MFB as the end of rapid combustion provides a safe reference point, 
as this location is not overly affected by parallel heat release processes taking place in the chamber during the so-called combustion termination. In the present work, further combustion indicators are used to aid the examination of soot formation. These are presented in the results and discussion section.

\section{RESULTS AND DISCUSSION}

\subsection{Analysis of Engine-Out Soot Measurements - Number Density}

The experimental results for engine-out total particle number density (N/cc), at part-load running conditions, are presented in this section. N/cc values, averaged upon three consistent steady-state test repetitions, are shown in figure 3 as a function of engine speed and load (BMEP). A contourplot type map has been used for the analysis. The average experimental records of N/cc are interpolated using a triangle-based cubic model over a uniform grid of speed and load points. The same approach has been used to presents other results in this paper. Data regarding spark ignition advance (CA degrees BTDC) and mixing time, calculated as time in ms between EOI and TDC of combustion, are presented in figures 4 and 5 . The process of "mixture preparation" includes fuel droplets vaporisation and mixing of air and combustible vapours to create a homogeneous and uniform mixture throughout the chamber. Mixture preparation may continue after the inception of combustion. Ignition timing and mixing timing constrain mixture preparation, hence are of significance in the process of soot formation. Three high-soot regions can be identified in the N/cc map of figure 3. The first is located in the top-left corner of the map, at low speed and high load. The second region is shaped as an island of high number density in the mid-speed, mid-load domain. The last one, showing a steep increase in soot particle number density, corresponds to top-right corner, the upper part-load domain.

\section{Figure 3}

\section{Figure 4}

\section{Figure 5}

Mid to low load (4.5 bar BMEP and below).

At the lowest engine speed investigated (1600 rev/min) and a fixed load of $4.5 \mathrm{bar}$, the comparatively long mixing time (about $28 \mathrm{~ms}$ ) allows the moderate amount of fuel injected (11.5 $\mathrm{mg}$ per cycle per cylinder) to vaporise and mix with the intake air, minimising the rate of soot nucleation. As speed increases, the available mixing time shortens, causing poorer mixture preparation. Although greater engine speed tends to mitigate these effects by stretching the combustion process over wider CA intervals, the increasingly advanced spark timing also leaves less time for mixing, as well as inducing higher temperature during combustion [15, 29, 30, 37]. When engine speed grows between 1600 and $3000 \mathrm{rev} / \mathrm{min}$ at $4.5 \mathrm{bar}$ BMEP, the net effect of these factors is a six-fold increase in soot $\mathrm{N} / \mathrm{cc}$ (to $6 \times 10^{6}$ particles/cc). As engine speed exceeds $3000 \mathrm{rev} / \mathrm{min}, \mathrm{N} / \mathrm{cc}$ decreases approaching levels as low as $2 \times 10^{6}$ at $3700 \mathrm{rev} / \mathrm{min}$. In this region, the mixing time is approximately constant (see figure 5) and the greater in-cylinder turbulence would enhance vaporisation and mixing of the moderate amount of fuel injected [37], reducing the rate of soot nucleation. At lower, fixed engine load (e.g. 2.5 bar BMEP) the small amount of fuel injected ( $7 \mathrm{mg}$ per cycle per cylinder) inhibits the formation of particulate matter, especially at the lower engine speeds when longer air-to-fuel mixing intervals are available. The distribution of soot $\mathrm{N} / \mathrm{cc}$ is remarkably similar to that at 4.5 bar BMEP, only scaled down as expected to lower concentrations.

\section{Higher load (7 bar BMEP and above)}

At a fixed engine load of 7 bar BMEP, the speed-dependent soot number density shows a characteristic $U$-shape distribution, common to all higher load cases. As the engine speed is reduced below $2600 \mathrm{rev} / \mathrm{min}$, the total number density rises towards a maximum level of $6.5 \times 10^{6}$ $\mathrm{N} / \mathrm{cc}$ at $1600 \mathrm{rev} / \mathrm{min}$. In spite of the longer time available for mixing, the large mass of fuel injected (between 17 and $22 \mathrm{mg}$ ) may cause a less effective process of mixture preparation. The greatly 
retarded spark timing in this region would also contribute to the recorded sharp number density increase. As the engine speed is increased above $2600 \mathrm{rev} / \mathrm{min}$, the major influence on N/cc is likely to be fuel spray-to-piston/liner impingement [10], whose effects start appearing at 7 bar BMEP, becoming much more significant as the injection mass and pressure grow (i.e. for greater engine load). As the load is raised to 9 bar in the high-speed end of the map (upper part-load domain), an early SOI (between 318 and 321 CA deg BTDC) has to be used for mixture preparation. The experimental data indicates a very sharp, ten-fold increase in soot number density (10 million particles per $\mathrm{cc}$ ) at these conditions. A possible explanation is that wall wetting becomes an increasingly important source of particulate matter.

\subsection{Combustion Characteristics and Correlation with Soot Number Density}

The correlation between soot formation and engine operating variables such as spark timing and injection strategy is evident and well-acknowledged [10, 15, 24, 28, 29, 30]. The following section focuses on exploring correlations between relevant combustion indicators and engine-out soot number density.

\section{Flame Development Angle}

The contour-plot map of FDA as a function of engine speed and load is presented in figure 6 . The development of combustion and its duration depend mostly upon the thermo-chemical state of the charge at the start of combustion. At fixed engine speed, an earlier start of combustion leads to smaller initial in-cylinder temperature and pressure, and ultimately to a longer development process. Higher engine speed at fixed load leads to greater chamber turbulence, which shows some beneficial effects on the rapidity of flame development; at the same time, greater speed tends to stretch the process over wider crank angle windows [36]. As clear from figures 4 and 6 , the net outcome is that the FDA shows a strong degree of correlation with ignition advance; the two quantities are linearly correlated and the FDA grows with a gradient of 0.7 CA degrees per 1 degree variation in spark advance. As engine speed and load are varied in the part-load envelope, the spark timing strategy is such that changes to the location where fast burning commence are minimised.

Despite being distorted by the bulk motion and corrugated by turbulence, during flame development the growing burned volume $\mathrm{V}_{\mathrm{b}}$ would be located approximately centrally, in a region of high turbulence. In homogeneous charge mode, this region would be conceivably well-mixed, and only a small proportion of soot is likely to form during the flame development stage. A crosscheck of figures 3 and 6 reveals that soot N/cc and FDA are, as expected, virtually independent of each other.

\section{Figure 6}

Rapid Burning Angle and Unburned Gas Temperature

In a gasoline spark ignition engine most of the charge burns at a fast pace during the so-called Rapid Burning Angle. It is during this phase, when the expanding flame front travels between the spark plug area and the far corners of the combustion chamber, that most soot particles would be nucleated. The duration of rapid combustion and the temperature of the unburned gases approaching (and being entrained into) the flame front, would exert an influence on soot nucleation rates if the process of mixture preparation remains unfinished when combustion commences. This is more likely to happen at medium to high engine load, i.e. with greater fuelling rates. The existence of sub-stoichiometric regions, segregated away from the central combustion space, would promote the nucleation of carbonaceous particles at the arrival of the flame front. A longer rapid burning duration leaves more time for mixture preparation, reducing soot formation. In this case, an increasing proportion of the process takes place along the expansion stroke at reduced unburned gas temperature. Because of smaller laminar flame velocity [36], the flame front travels at reduced speed, reaching the remote areas of the combustion chamber in a longer time interval. Reduced unburned gas temperature would also cause lower flame-front temperature, reducing the soot nucleation rate via a second mechanism [15, 27, 30]. On the contrary, a shorter rapid combustion interval would be located closer to TDC, animated by hotter unburned gases. Both greater flame velocity and temperature would promote the nucleation of soot particles. 
Two separate quantities, RBA and maximum unburned gas temperature, $(\mathrm{Tu})_{\max }$ (corresponding to the location of maximum in-cylinder pressure), are considered to further the analysis of soot formation. The contour-plot maps of RBA and $(\mathrm{Tu})_{\max }$ as a function of engine speed and load are presented in figures 7 and 8 , respectively. The unburned gas temperature is modelled from spark timing, assuming polytropic compression during combustion. Figure 7 depicts a fast burning engine, with RBA varying only between 14 and 21 CA degrees. As expected, RBA increases with increasing engine speed, whereas it appears relatively constant as the BMEP is varied in the range 2.5 to 9 bar. The expected decrease in duration, due to greater charge density as engine load rises, vanishes in the present case as an effect of decreasing spark advance, which typically would cause a lengthier burning process [38]. As speed and load are varied, different ignition setting is used so that peak pressure locates consistently in a narrow crank angle window after TDC (8 to 18 CA deg ATDC), ensuring high thermal efficiency [36].

\section{Figure 7}

\section{Figure 8}

Parallel examination of figures 3,7 and 8 reveals a significant relationship between soot number density and combustion characteristics. The results suggest that incomplete mixture preparation enables increased nucleation at those conditions where the rapid burning phase is shorter and, correspondingly, the unburned gas temperature is greater. This is particularly evident in the midspeed, mid-load region where a shorter and hotter rapid combustion causes the establishment of an island of high soot N/cc. Remarkably, as the engine speed increases over or decreases below $3000 \mathrm{rev} / \mathrm{min}$ at medium load (between 4 and 5 bar bmep), rapid combustion slows down, enabling lower $(\mathrm{Tu})_{\max }$. As anticipated above, these two separate mechanisms discourage the nucleation of soot particles. Consistent phenomena determine the characterisation of soot number density at low speed (1600 to $2000 \mathrm{rev} / \mathrm{min}$ ) and higher load ( $6.5 \mathrm{bar}$ and above), i.e. in the top left corner of the $\mathrm{N} / \mathrm{cc}$ map. Here, retarded spark timing and quick development process cause short rapid combustion and greater unburned gas temperature; as expected, on account of a high fuelling rate at high load, an incomplete mixture preparation process enables more soot particles to be formed during the RBA. As the engine speed is increased at high load (in excess of 7 bar), the RBA extends into the expansion stroke towards regions of lower temperature. Correspondingly, soot $\mathrm{N} / \mathrm{cc}$ decreases as expected until a very different phenomenon, namely spray impingement, is likely to occur. The experimental soot measurements suggest that the detrimental influence of spray impingement supersedes the beneficial effects of high in-cylinder turbulence, lengthened combustion duration and comparatively lower combustion temperatures.

\section{Rapid Combustion up to Peak Pressure $\left(\mathrm{RBP}_{\max }\right)$}

Reference to RBA has been used so far as this represents a commonly used combustion duration indicator. However, the data suggests that a separate parameter may be more relevant. Figure 9 shows the contour-plot map of $\mathrm{RBP}_{\max }$, calculated as the crank angle interval between $10 \% \mathrm{MFB}$ and the location of peak pressure. Peak pressure, compared to the location where $90 \%$ of the fuel mass has been consumed, should provide a safer indication of the flame front reaching the furthest walls of the combustion chamber. Past this point, the rate of combustion is forced to reduce, alongside with the flame temperature. A comparative examination of figure 3 and 9 indicates that, in spite of its narrow range of variation, limited to $4 \mathrm{CA}$ degrees, $\mathrm{RBP}_{\max }$ shows a remarkable degree of correlation with soot number density. Bar the top-right corner of the N/cc map (potential spray impingement) and the region where BMEP $<3$ bar (small mass of fuel injected, enabling a fuller mixture preparation), $\mathrm{RBP}_{\max }$ and soot $\mathrm{N} / \mathrm{cc}$ are inversely correlated and the regions of greater N/cc are almost invariably identified by shorter $\mathrm{RBP}_{\max }$. If a relatively course $(20 \times 20)$ grid is used for the cubic interpolation of the experimental data for soot N/cc and the calculated data for $\mathrm{RBP}_{\max }$, a speculative distribution of N/cc as a function of $\mathrm{RBP}_{\text {max }}$ can be created, as presented in figure 10. In spite of the high scatter, this linear relationship suggests that the bulk of the soot formation process is restricted to, and would depend on the length of, the rapid burning process up to the point where the bulk of the combustion chamber has been swiped by the expanding flame front. 


\section{Figure 9}

\section{Figure 10}

\subsection{Analysis of Engine-Out Soot Measurements - Particle Size and Mass}

The measurements of size-resolved soot number density distribution have been summarised in figure 11, which shows the percent distribution of number density upon five relevant particle diameter bins. In line with the relevant literature [10, 15, 24, 28, 29], the vast majority of soot emitted by the wall-guided GDI test engine can be considered as primary particles in the 10 to 100 $\mathrm{nm}$ diameter range, whereas in excess of $55 \%$ is emitted in nucleation mode (below $50 \mathrm{~nm}$ ). Although the distribution of small particles (size between 10 and $20 \mathrm{~nm}$ ) is highly fragmented, a clear overall trend can be seen and, at all operating conditions except one, an average of $42 \%$ of particles is emitted in the 20 to $50 \mathrm{~nm}$ diameter bin. Interestingly, a drop in number density of particles greater than $100 \mathrm{~nm}$ is consistent for all the 16 cases. The particle size distribution shows a slightly asymmetric shape, which peaks in the $20-50 \mathrm{~nm}$ size bin; similar trends have been reported by Maricq et al. [15]. For the $3700 \mathrm{rev} / \mathrm{min}$ cases, less than $10 \%$ of the soot agglomerates reach a size greater than $100 \mathrm{~nm}$. The higher late-cycle oxidation, due to the higher exhaust gas temperature, can explain the decrease in particle size as the speed is increased. The light load cases of $30 \mathrm{Nm}$ shift the distribution towards small particle size, i.e. below $50 \mathrm{~nm}$, probably due to the reduced locally rich regions of the fuel mixture and the burning of completely volatilized fuel droplets. Nevertheless, the only engine condition to produce measurable particle number in the size range above $300 \mathrm{~nm}$ (proper cluster or chain-like aggregation mode) was the lowest engine speed/load point, i.e. $1600 \mathrm{rev} / \mathrm{min}$ and $30 \mathrm{Nm}$. Differences in nanoparticle size may reflect a combination of different operating conditions, combustion temperatures and chemical species contributing to particle growth at various stages. It is interesting to note that the peak values of number density are much lower than typical $130 \mathrm{~nm}$ soot agglomerates from diesel engines [39, 40]; possibly because the hydrocarbons involved are more volatile compared to diesel.

\section{Figure 11}

The contour-plot map of exhaust soot Geometrical Mean Diameter, as a function of engine speed and load, is given in figure 12. The analysis of GMD at part-load operating conditions is complex as the influence of engine operating variables is quite subtle. The literature surveyed above suggests two variables, namely ignition timing and exhaust gas temperature, are most significant in determining soot particle size [15,30]. The extent of their influence would depend on the rate of nucleation, as high concentration of soot should enhance the coagulation and/or aggregation of particles [15]. Contrarily to this premise, the data collected in the present work contains no strong evidence of a positive association between soot concentration and size, as indicated by the GMD. The correlation between engine speed, load and exhaust gas temperature, measured close to the point of access for soot emissions sampling, is presented in figure 13. Spark timing affects how the combustion process is phased about TDC, determining the resulting post-combustion gas temperature. The influence of ignition timing on exhaust temperature is, in the present case, mitigated by the changes in engine speed and load. Nevertheless, the exhaust gas temperature is seen to increase with increasing engine speed and load. As explained below, this has the effect of promoting post-flame oxidation [15, 30].

\section{Figure 12}

\section{Figure 13}

In figure 12 three GMD regions have been identified. Region 1, at low engine speed and mid to high load, is characterised by greater GMD in the range 50 to $60 \mathrm{~nm}$. Region 2 is the upper partload domain, where spray impingement is likely to be dominant; here, the GMD sharply decreases reaching size as low as $23 \mathrm{~nm}$. Region 3 , at medium to low load and increasing speed, sees a relatively constant average particle size, between 35 and $40 \mathrm{~nm}$. In region 1 , as the engine load is increased at constant speed, the GMD firstly grows reaching a peak at 6.5 bar BMEP, and then 
decreases. Remarkably, a strong resemblance is found between the distribution of GMD and that of unburned gas temperature, (Tu $)_{\max }$ (see figure 8). As suggested by Pei et al. [33], greater combustion temperature (of which (Tu) max gives an indication) would favour the formation of particles in the accumulation mode. The inherent stratification of fuel at low speed and mid-to-high load leads to greater particle inception, while simultaneously the high combustion temperature enhances coagulation and/or agglomeration [41]. This is also suggested by the results presented in figure 11, where for an engine speed of $1600 \mathrm{rev} / \mathrm{min}$ and a load of $90 \mathrm{Nm}, 95 \%$ of particles are emitted with size above $20 \mathrm{~nm}$. The relatively low incidence of post-flame oxidation at low engine speed (see figure 13) allows the particles to conserve an increased size when emitted. As the GMD map is swept to the right of region 1, temperature $(T u)_{\max }$ decreases, and the GMD also decrease, but with a smaller gradient of descent, possibly mitigated by the effects of increasing speed as well as earlier fuel injection [15, 24, 30]. As the engine speed is further increased, the influence of greater exhaust temperature on post-flame surface oxidation becomes more important, reaching its apex in region 2, for temperature in excess of $1000 \mathrm{~K}$. Comparative examination of figures 3, 11 and 12 reveals that, at high speed and load, high concentrations of exhaust soot (up to 10 million particles per cc) are emitted, mostly with very small size in the nucleation mode range (between 23 and $40 \mathrm{~nm}$ ). High fuel stratification due to extended spray-wall interaction, along with high exhaust gas temperature, are thought to be responsible for the "upper part-load" soot particle characterisation. As shown in figure 11, at the highest engine speed and load investigated (3700 $\mathrm{rev} / \mathrm{min}$ and $120 \mathrm{Nm}$ ), only $10 \%$ of particles are emitted with size above $50 \mathrm{~nm}$. As the "upper partload" operating range is often swept across as a result of typical stop-and-run driving pattern in urban areas, region 2 must be identified as an area of concern. The characterisation of GMD in region 3 is less clear. The experimental results suggest that, as the engine speed is increased at light-to-mid load, the influence of worsened mixing, which would normally lead to greater average size [41], is mitigated by that of higher oxidation, as a result of higher exhaust gas temperature. In agreement with Pei et al. [33], advanced ignition timing and greater combustion temperature bear no visible influence on the average size of the engine-out soot in this region. The net result of such multi-faceted phenomena is that in region 3 the GMD remains approximately constant.

Figure 14 shows the contour-plot map of soot mass concentration in $\mu \mathrm{g} / \mathrm{cc}$ as a function of engine operating conditions. Bar the high speed/high load impingement area, the mass concentration closely follows the distribution of particles number density and, to a lesser extent, that of average particle size. In terms of soot mass, two regions of concern can be identified. The first one, at high engine load and low speed, assumes a distinctive triangular pattern where, relatively to the lowest baseline value, soot mass concentration shows a sharp four-fold increase. The second one, at moderate speed and load, corresponds to the island of high number density shown in figure 3 . Here, soot mass concentration shows a three-fold increase. Finally, due to very low GMD, low soot mass is emitted in the upper part-load corner, in spite of very high particle number.

\section{Figure 14}

Further work, already being undertaken by the Authors, aims at a more comprehensive assessment of the connection between mixture preparation, combustion characteristics and soot formation. Further work is carried out on two fronts. On one hand modelling work, using CFD for a deeper insight into mixture preparation and combustion; on the other hand further experimental work, aimed at measuring engine-out soot over a more refined part-load grid.

\section{Conclusions}

Experimental measurements of size-resolved soot number density distribution have been taken from a modern Euro IV, wall-guided GDI engine, using 95 RON gasoline fuel. Engine tests covered a large portion of the part-load running envelope, with engine speed in the range 1600 to 3700 $\mathrm{rev} / \mathrm{min}$ and torque in the range 30 to $120 \mathrm{Nm}$ (BMEP between 2.36 and $9.44 \mathrm{bar}$ ). All tests were carried out at steady-state, fully-warm conditions, and the engine was operated in stoichiometric and homogeneous mode, with fuel injection early in the intake stroke. The primary aim of this study 
has been to investigate the correlation between engine-out soot measurements and combustion characteristics.

The results indicate the existence of a linear correlation between rapid combustion duration and total soot particle number concentration for engine load in excess of 3 bar BMEP. This is enabled by incomplete gas-phase mixture preparation at the start of combustion. Higher total particle number density is invariably correlated to faster rapid combustion. On average, a six-fold increase in number density between 1.0 and $6.0 \times 10^{6}$ particles per $c c$ arises from shortening the rapid duration of 4 CA degrees. A clear association is also found between greater unburned gas temperature feeding the flame-front and greater rate of soot formation.

The correlation between combustion characteristics and soot number density disappears in the upper part-load range, for engine speed in excess of $3000 \mathrm{rev} / \mathrm{min}$ and load in excess of $7 \mathrm{bar}$ BMEP. Very early SOI (315 CA deg BTDC or ealier), used to enable better mixing at high speed and load, causes fuel spray impingement, possibly wall wetting and much higher soot nucleation rates, likely as a results of pool-fire.

The total soot number density measured at part-load was between $1.0 \times 10^{6}$ and $1.0 \times 10^{7}$ particles per cc, with the greatest levels measured in the upper part-load range. The Geometrical Mean Diameter varied between 23 and $60 \mathrm{~nm}$. The greatest average particle size, between 50 and 60 $\mathrm{nm}$, is measured at low engine speed and mid to high engine load. Particles emitted in the upper part-load domain were on average very small (GMD between 40 and $23 \mathrm{~nm}$ ).

In terms of soot emissions, three main regions of concern have been identified within the part-load running envelope: 1. the higher load-lower speed range and 2. the mid load-mid speed range, where high nucleation rates induce copious increases of engine-out soot mass; 3 . the upper partload corner, where the highest levels of particle numbers were recorded.

Beside the necessity of improved combustion systems design, the results suggest that for given part-load engine conditions, alterations of combustion duration may be induced to conceivably obtain sizeable reduction of exhaust soot. As the more recent spray-guided GDI technology appears to suffer, though to a lesser extent, from similar soot formation mechanisms (imperfect mixing, pool-fire), the analysis presented here carries wider potential relevance.

\section{References}

[1] Brehob, D. D., Stein, R. A., Haghgooie, M., Stratified-Charge Engine Fuel Economy and Emission Characteristics, SAE Technical Paper 982704, 1998

[2] Brugge, D., Durant, J., Rioux, C., Near-highway pollutants in motor vehicle exhaust: A review of epidemiologic evidence of cardiac and pulmonary health risks, Environmental Health, 6(23), 2007

[3] Seaton, A., Godden, D., MacNee, W., Donaldson, K., Particulate air pollution and acute health effects, The Lancet, 345(8943): 176-178, 1995

[4] Heyder, J., Deposition of Inhaled Particles in the Human Respiratory Tract and Consequences for Regional Targeting in Respiratory Drug Delivery, Proceedings of the American Thoracic Society, 1: 315-320, 2004

[5] Ferin, J., Oberdörster, G., Penney, D. P., Pulmonary Retention of Ultrafine and Fine Particles in Rats, American Journal of Respiratory Cell and Molecular Biology, 6(5): 535-542, 1992

[6] Nel, A., Xia, T., Madler, L., Li, N., Toxic Potential of Materials at the Nano-level, Science, 311(5761): 622-627, 2006

[7] Raaschou-Nielsen, O. et al., Air pollution and lung cancer incidence in 17 European cohorts: prospective analyses from the European Study of Cohorts for Air Pollution Effects (ESCAPE). The Lancet Oncology, 10 July 2013 (Article in Press DOI: 10.1016/S1470-2045(13)70279-1)

[8] Schreiber, D., Forss, A., Mohr, M., Dimopoulos, P., Particle Characterisation of Modern CNG, Gasoline and Diesel Passenger Cars, SAE Technical Paper 2007-24-0123, 2007 
[9] Piock, W., Hoffmann, G., Berndorfer, A., Salemi, P., Fusshoeller, B., Strategies Towards Meeting Future Particulate Matter Emission Requirements in Homogeneous Gasoline Direct Injection Engines, SAE Int. J. Engines 4(1): 1455-1468, 2011

[10] Choi, K., Kim, J., Myung, C. L., Lee, M., Kwon, S., Lee, Y., Park, S., Effect of the mixture preparation on the nanoparticle characteristics of gasoline direct-injection vehicles, Part D: JAuto, 226(11): 1514-1524, 2012

[11] Peckham, M. S., Finch, A., Campbell, B., Price, P., Davies, M. T., Study of Particle Number Emissions from a Turbocharged Gasoline Direct Injection (GDI) Engine Including Data from a FastResponse Particle Size Spectrometer, SAE Technical Paper 2011-01-1224, 2011

[12] Williams, B., Ewart, P., Wang, X., Stone, R., Ma, H., Walmsley, H., Cracknell, R., Stevens, R., Richardson, D., Fu, H., Wallace, S., Quantitative planar laser-induced fluorescence imaging of multi-component fuel/air mixing in a firing gasoline-direct-injection engine: Effects of residual exhaust gas on quantitative PLIF, Combustion and Flame, 157(10): 1866-1878, 2010

[13] Velji, A., Yeom, K., Wagner, U., Spicher, U. et al., Investigations of the Formation and Oxidation of Soot Inside a Direct Injection Spark Ignition Engine Using Advanced LaserTechniques, SAE Technical Paper 2010-01-0352, 2010

[14] Lucchini, T., D'Errico, G., Onorati, A., Bonandrini, G., Venturoli, L., Di Gioia, R., Development and application of a computational fluid dynamics methodology to predict fuel-air mixing and sources of soot formation in gasoline direct injection engines, Int. J. Engine Res., published online October 15, 2013

[15] Maricq, M. M., Podsiadlik, D. H., Brehob, D. D., Haghgooie, M., Particulate Emissions from a Direct-Injection Spark-Ignition (DISI) Engine, SAE technical Paper 1999-01-1530, 1999

[16] Braisher, M., Stone, R., Price, P., Particle Number Emissions from a Range of European Vehicles, SAE Technical Paper 2010-01-0786, 2010

[17] Clague, A.D.H., Donnet, J.B., Wang, T.K., Peng, J.C.M., A comparison of diesel engine soot with carbon black, Carbon, 37(10): 1553-1565, 1999

[18] Heywood, J.B., Internal Combustion Engine Fundamentals, Boston: McGraw-Hill International, Automotive Technology Series, 1988

[19] Reavell, K., hands, T., Collings, N., A Fast response Particulate Spectrometer for Combustion Aerosols, SAE Technical Paper 2002-01-2714, 2002

[20] Gonzalez-Oropeza, R., Hill, B. J., Hassaneen, A. E., Samuel, S., Morrey, D., Gasoline Engine Particulate Emission and Exhaust Gas Speciation, SAE Technical Paper 2009-01-2670, 2009 [21] Price, P., Stone, R., Collier, T., Davies, M., Scheer, V., Dynamic Particulate Measurements from a DISI Vehicle: A Comparison of DMS500, ELPI, CPC and PASS, SAE Technical Paper 2006-01-1077, 2006

[22] Cambustion Ltd, DMS 500 User Manual, Version 2.6

[23] Baron, P.A. Willeke, K., Aerosol Measurement. Principles, Techniques, and Applications, New York: Wiley, 2001

[24] Barone, T. L., Storey, J.M.E., Youngquist, A.D., Szybist, J.P., An analysis of direct-injection spark-ignition (DISI) soot morphology, Atmospheric Environment, 49: 268-274, 2012

[25] Keskinen, J., Pietarinen, K., Lehtimäki, M., Electrical Low Pressure Impactor, J. Aerosol Sci., 23(4): 353-360, 1992

[26] Witze, P., Chase, R., Maricq, M. M., Podsiadlik, D. et al., Time-Resolved Measurements of Exhaust PM for FTP-75: Comparison of LII, ELPI, and TEOM Techniques, SAE Technical Paper 2004-01-0964, 2004

[27] Kayes, D., Hochgreb, S., Mechanisms of Particulate Matter Formation in Spark-Ignition Engines. 1. Effect of Engine Operating Conditions, Environmental Science \& Technology, 33(22): 3957-3967, 1999

[28] Graskow, B. R., Kittelson, D. B., Ahmadi, M. R., Morris, J. E., Exhaust Particulate Emissions from a Direct Injection Spark Ignition Engine, SAE Technical Paper 1999-01-1145, 1999

[29] Price, P., Stone, R., Collier, T., Davies, M., Particulate Matter and Hydrocarbon Emissions Measurements: Comparing First and Second Generation DISI with PFI in Single Cylinder Optical Engines, SAE Technical Paper 2006-01-1263, 2006

[30] Farron, C., Matthias, N., Foster, D., Andrie, M., Krieger, R., et al., Particulate Characteristics for Varying Engine Operation in a Gasoline Spark Ignited, Direct Injection Engine, SAE Technical Paper 2011-01-1220, 2011 
[31] Whitaker, P., Kapus, P., Ogris, M., Hollerer, P., Measures to Reduce Particulate Emissions from Gasoline DI engines, SAE Technical Paper 2011-01-1219, 2011

[32] Sabathil, D., Koenigstein, A., Schaffner, P., Fritzsche, J., Doehler, A., The Influence of DISI Engine Operating Parameters on Particle Number Emissions, SAE Technical Paper 2011-01-0143, 2011

[33] Yi-Qiang Pei, Jing Qin, and Suo-Zhu Pan, Experimental study on the particulate matter emission characteristics for a direct-injection gasoline engine, Proc IMechE Part D: J Automobile Engineering, published online January 30, 2014

[34] Chen, L., Stone, R., Richardson, D., A study of mixture preparation and PM emissions using a direct injection engine fuelled with stoichiometric gasoline/ethanol blends, Fuel, 96: 123-130, 2012 [35] Shayler, P. J., Wiseman, M. W., MA, T., Improving the Determination of Mass Fraction Burnt, SAE Technical Paper 900351, 1990

[36] Bonatesta, F., Premixed Combustion in Spark Ignition Engines and the Influence of Operating Variables, Book Chapter in: Advances in Internal Combustion Engines and Fuel Technologies, $\mathrm{H}$. K. Ng (Ed.), ISBN: 978-953-51-1048-4, InTech, 2013

[37] Jia, M., Li, Y., Xie, M., Wang, T., Numerical evaluation of the potential of late intake valve closing strategy for diesel PCCI (premixed charge compression ignition) engine in a wide speed and load range, Energy, 51: 203-215, 2013

[38] Bonatesta, F., Waters, B., Shayler, P. J., Burn Angles and Form Factors for Wiebe Function Fits to Mass Fraction Burned Curves of a Spark-Ignition Engine with Variable Valve Timing, Int. J. Engine Res., 11(2): 177-186, 2010

[39] La Rocca, A., Di Liberto, G., Shayler, P.J., Fay, M.W., The Nanostructure Of Soot-In-Oil Particles And Agglomerates From An Automotive Diesel Engine, Tribology International, 61, May 2013: 80-87, 2013

[40] La Rocca, A., Di Liberto, G., Shayler, P.J., Parmenter, C.D.J., Fay, M.W. Application of nanoparticle tracking analysis platform for the measurement of soot-in-oil agglomerates from automotive engines, Tribology International, 70: 142-147, 2014

[41] Maricq, M. M., Harris, S. J., and Szente, J. J., Soot size distributions in rich premixed ethylene flames, Combustion and Flame, 132: 328-342, 2003 


\begin{tabular}{|c|c|}
\hline AFR & Air Fuel Ratio \\
\hline ATDC & After Top Dead Centre \\
\hline BMEP & Brake Mean Effective Pressure \\
\hline BTDC & Before Top Dead Centre \\
\hline CA & Crank Angle \\
\hline CPC & Condensation Particle Counter \\
\hline DISI & Direct Injection Spark Ignition \\
\hline DMA & Differential Mobility Analyser \\
\hline DMS & Differential Mobility Spectrometer \\
\hline DPF & Diesel Particulate Filter \\
\hline ECU & Engine Control Unit \\
\hline ELPI & Electrostatic Low Pressure Impactor \\
\hline EOC & End of Combustion \\
\hline EOI & End of Injection \\
\hline FDA & Flame Development Angle \\
\hline GDI & Gasoline Direct Injection \\
\hline GMD & Geometric Mean Diameter \\
\hline IT & Injection Timing \\
\hline IVC & Intake Valve Closing \\
\hline MFB & Mass Fraction Burned \\
\hline NEDC & New European Drive Cycle \\
\hline PAH & Polycyclic Aromatic Hydrocarbons \\
\hline PFI & Port Fuel Injection \\
\hline PM & Particulate Matter \\
\hline RBA & Rapid Burning Angle \\
\hline $\mathbf{R B P}_{\max }$ & Rapid Burning Angle at $\mathrm{P}_{\max }$ \\
\hline SMPS & Scanning Mobility Particle Sizer \\
\hline soc & Start of Combustion \\
\hline sol & Start of Injection \\
\hline
\end{tabular}


TDC Top Dead Centre

TEM Transmission Electron Microscopy

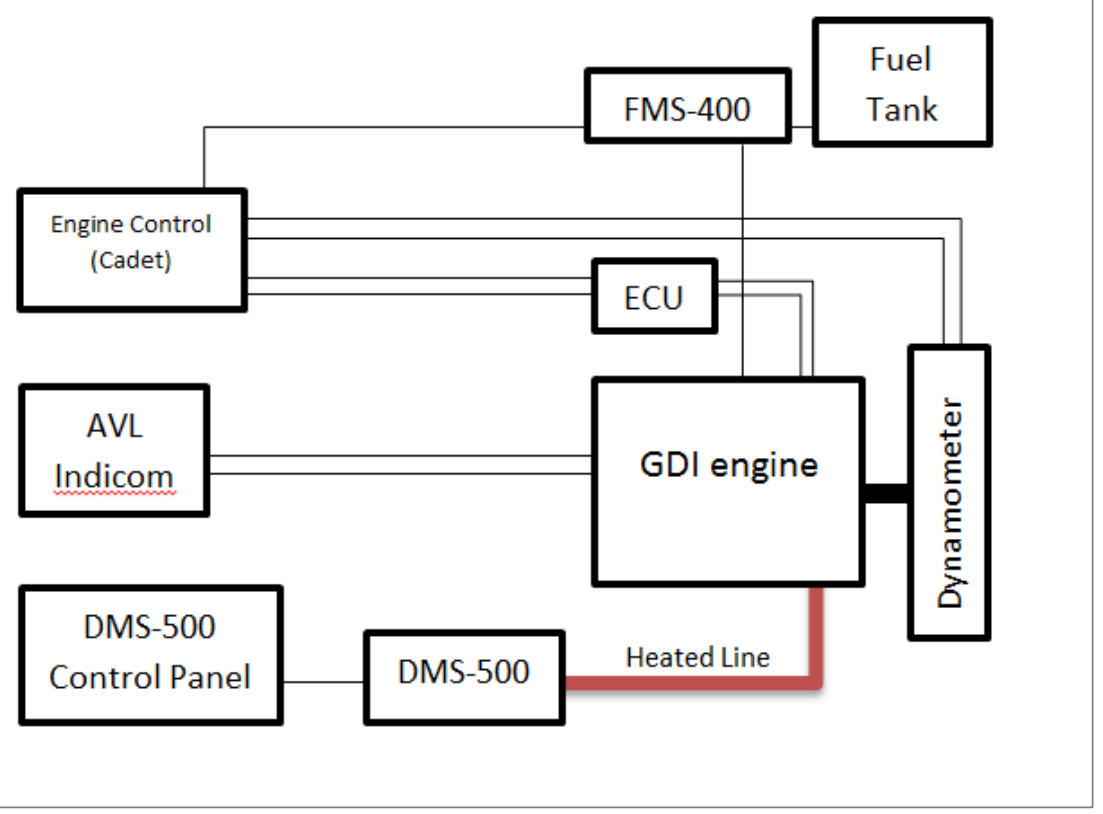

Figure 1. Schematic of engine rig experimental setup

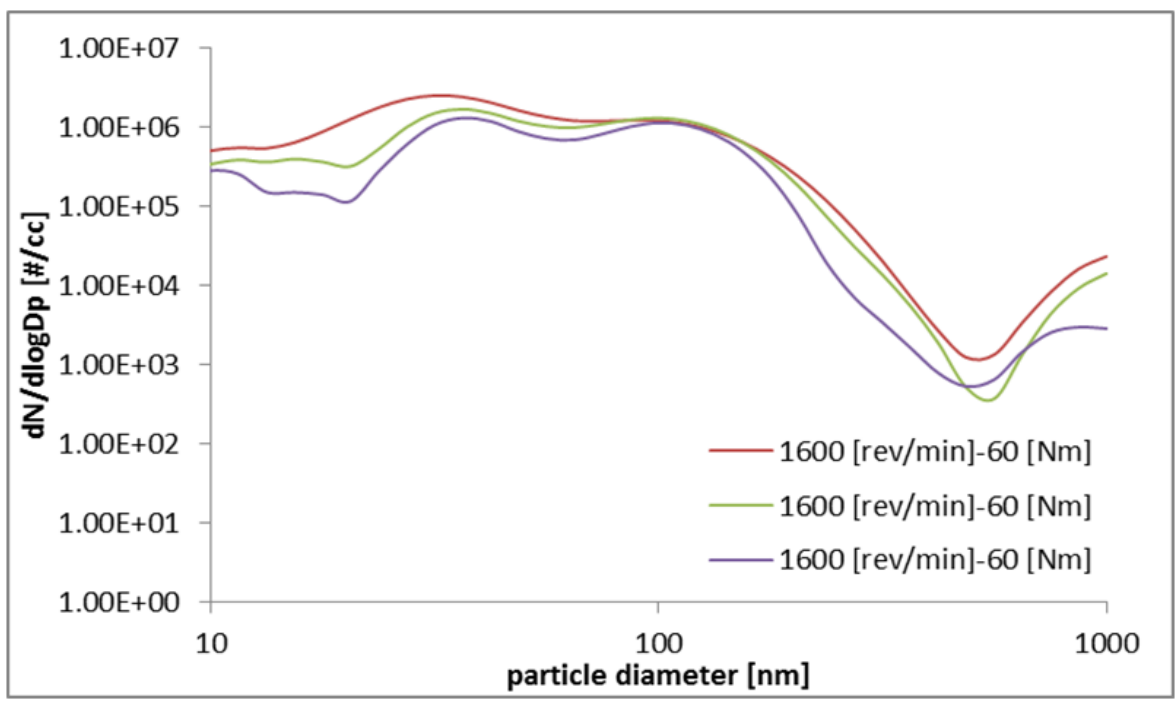

Figure 2. Repetitions of time-averaged, size-resolved engine-out soot number density distributions, at engine speed of $1600 \mathrm{rev} / \mathrm{min}$ and load of $60 \mathrm{Nm}$. On the horizontal axis is the electrical mobility equivalent diameter in $\mathrm{nm}$; on the vertical axis, the number density $\mathrm{N} / \mathrm{cc}$, normalized with the differential interval of the logarithm of particle size, $\mathrm{dN} / \mathrm{dlogDp}$. 


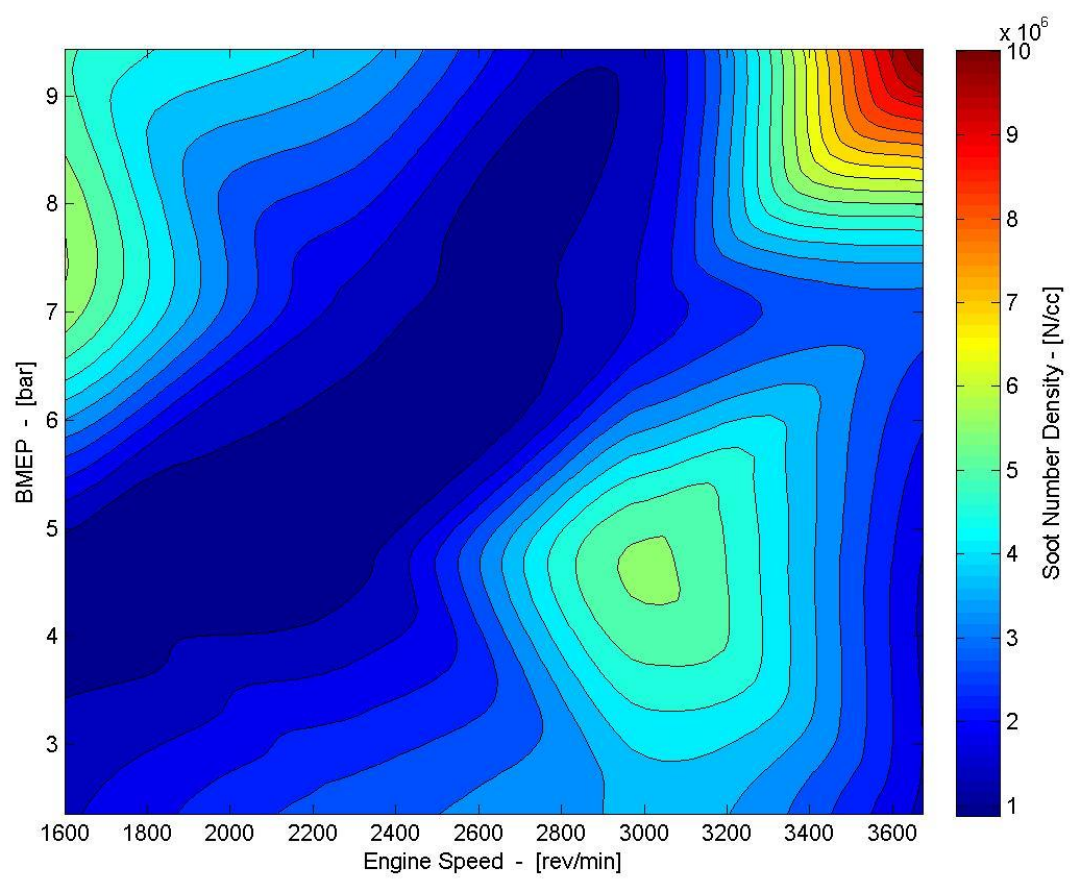

Figure 3. Experimental soot number density as a function of engine speed and load (BMEP). Measured particles with diameter smaller than $10 \mathrm{~nm}$ are excluded from the analysis.

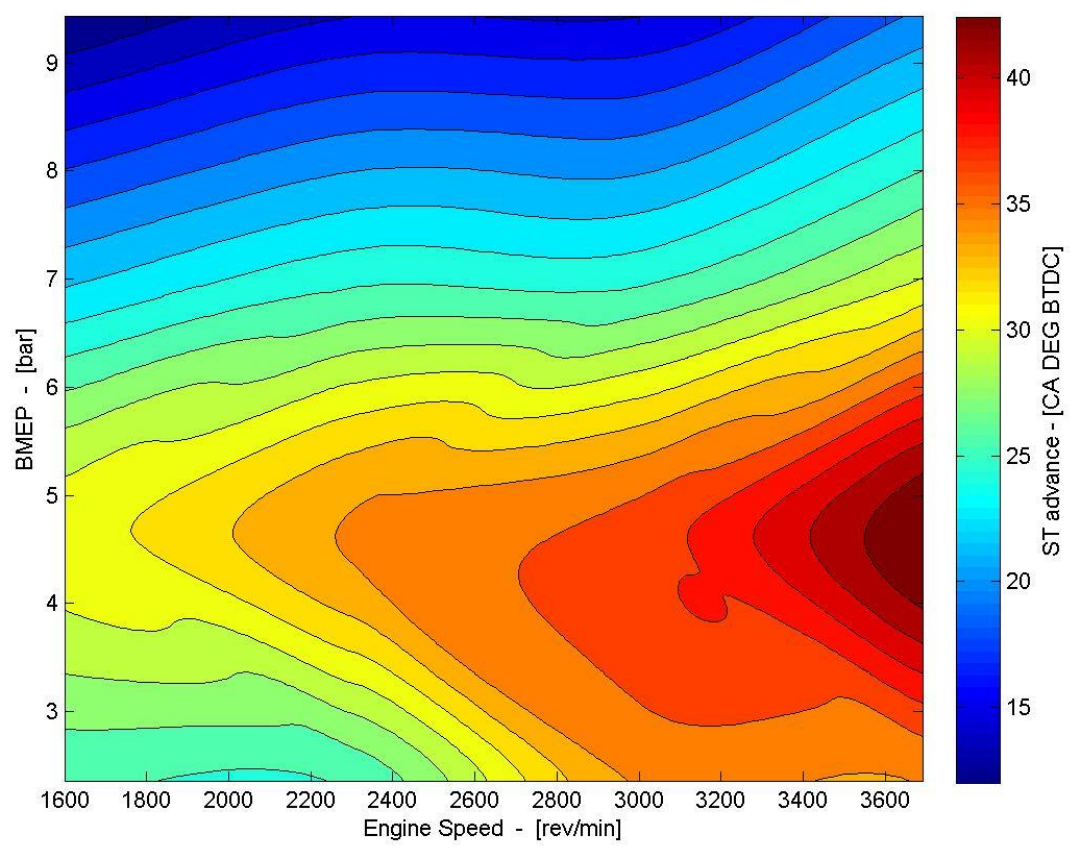

Figure 4. Spark Timing (ST) advance as a function of engine speed and load (BMEP). 


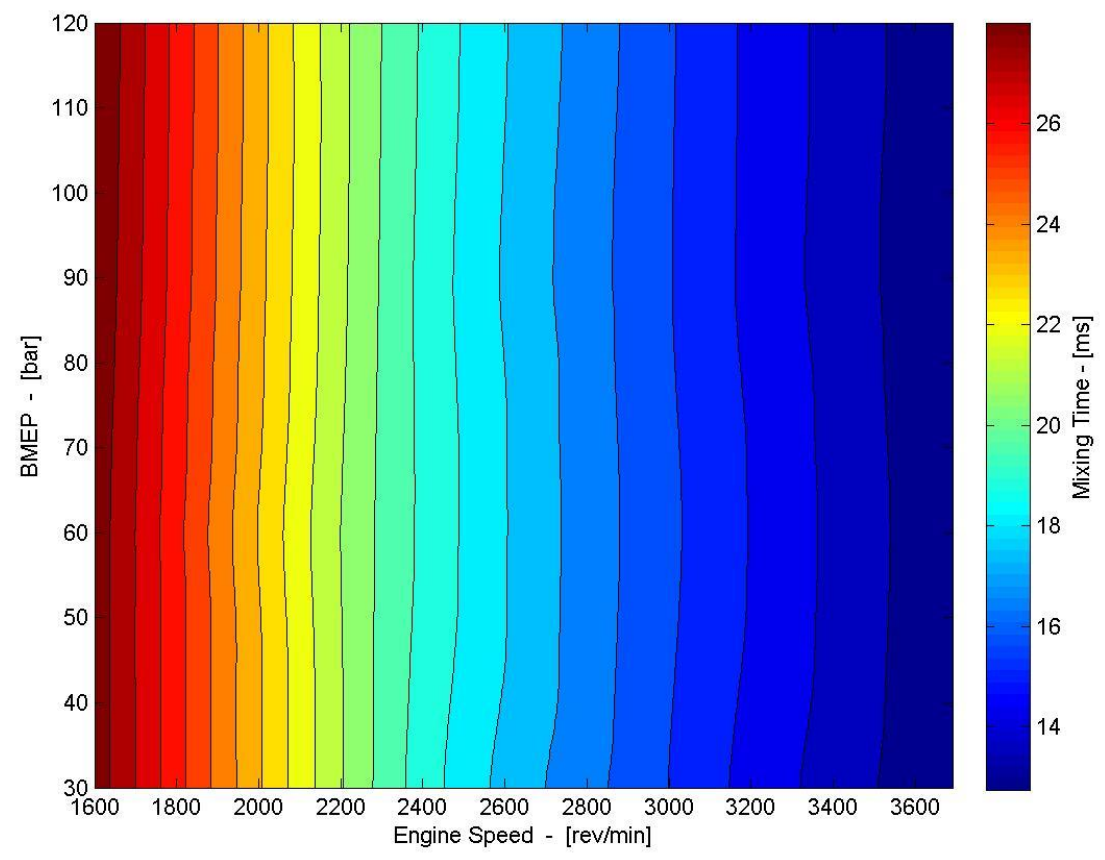

755

Figure 5. Mixing time (time between EOI and TDC of combustion) as a function of engine speed and load (BMEP).

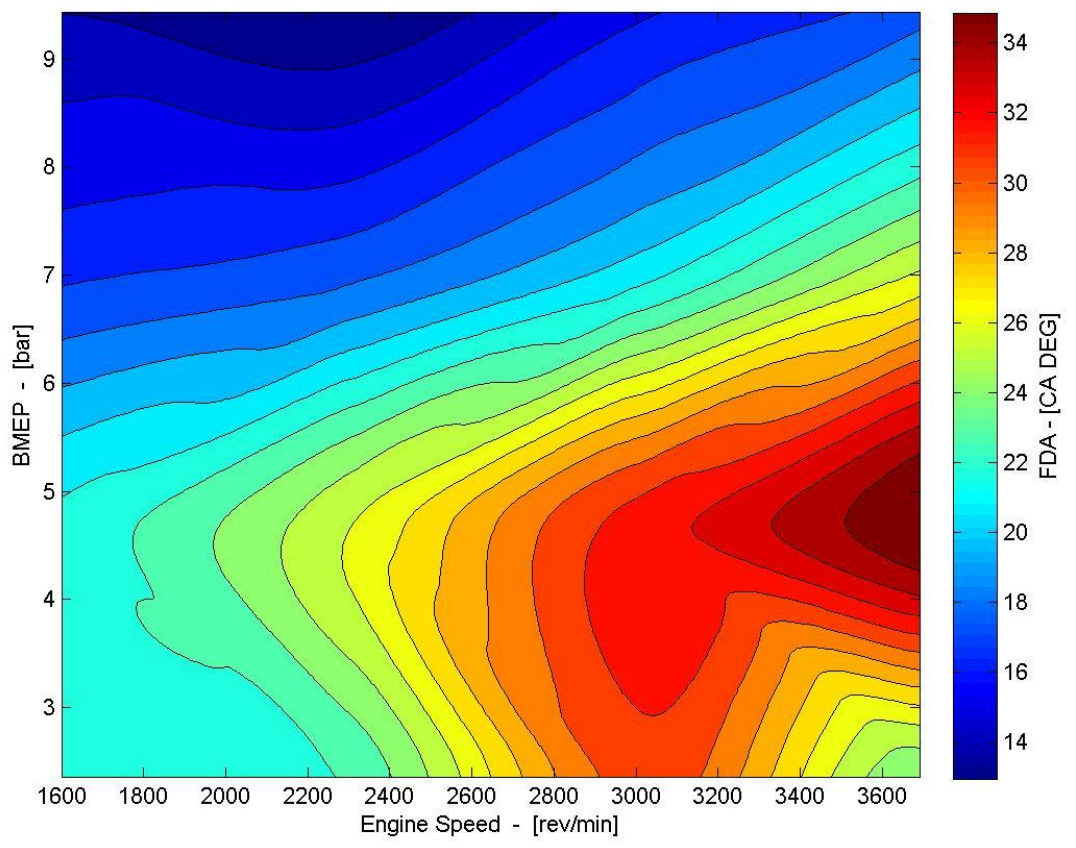

Figure 6. Flame Development Angle (FDA), as a function of engine speed and load (BMEP). 


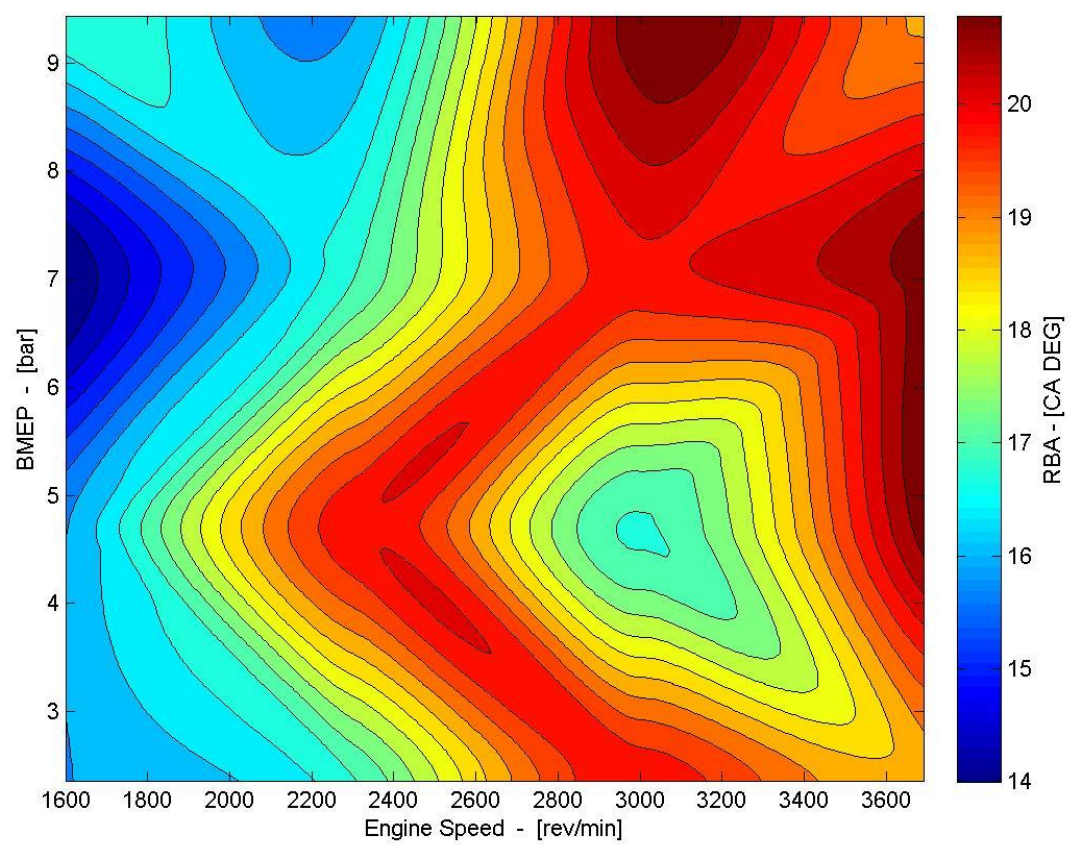

762

763 764
Figure 7. Rapid Burning Angle (RBA), as a function of engine speed and load (BMEP).

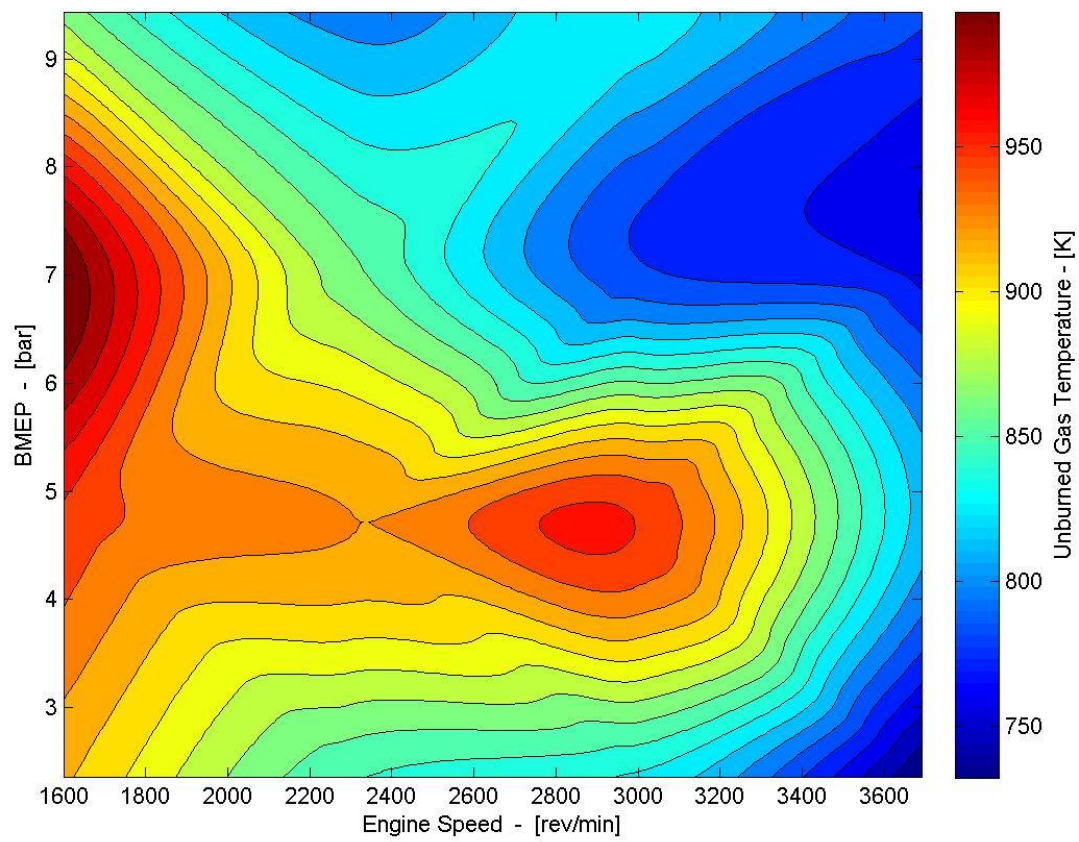

Figure 8. Modelled unburned gas temperature at the end of the rapid combustion phase, as a function of engine speed and load (BMEP). 


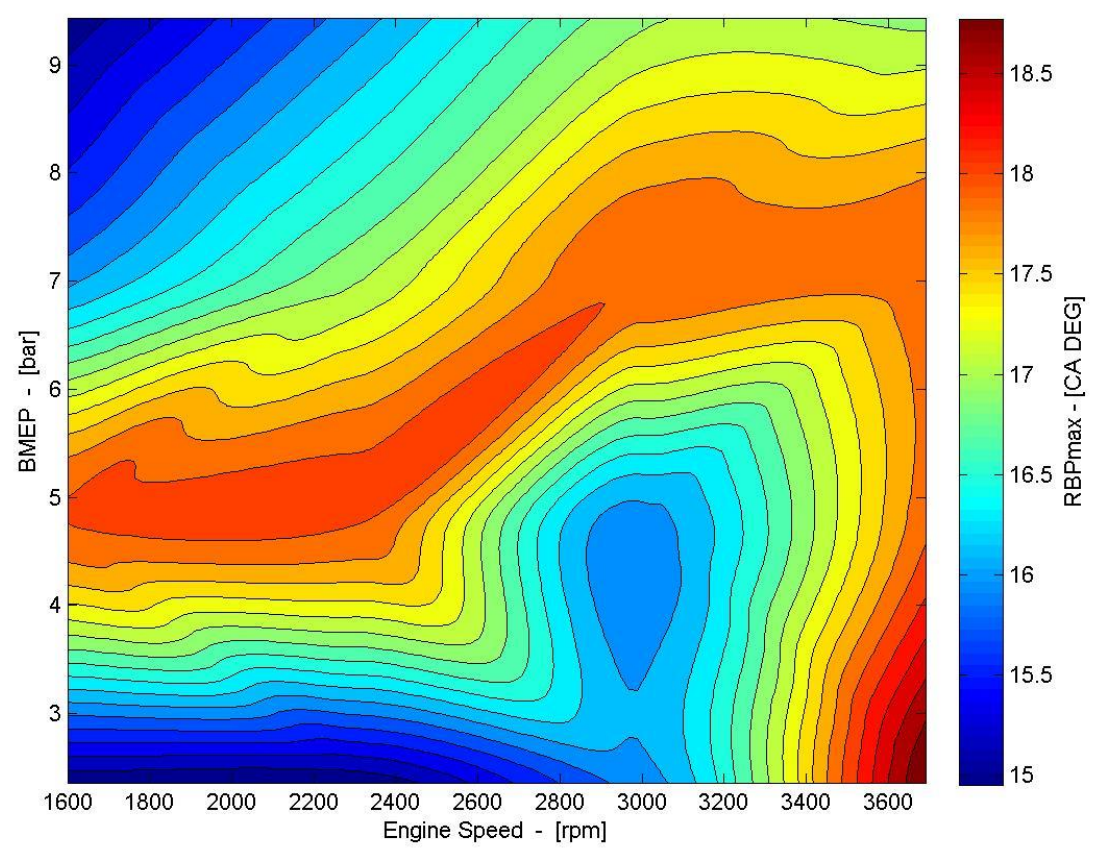

Figure 9. Crank angle interval between $10 \%$ MFB and location of peak pressure $\left(\mathrm{RBP}_{\max }\right)$, as a function of engine speed and load (BMEP).

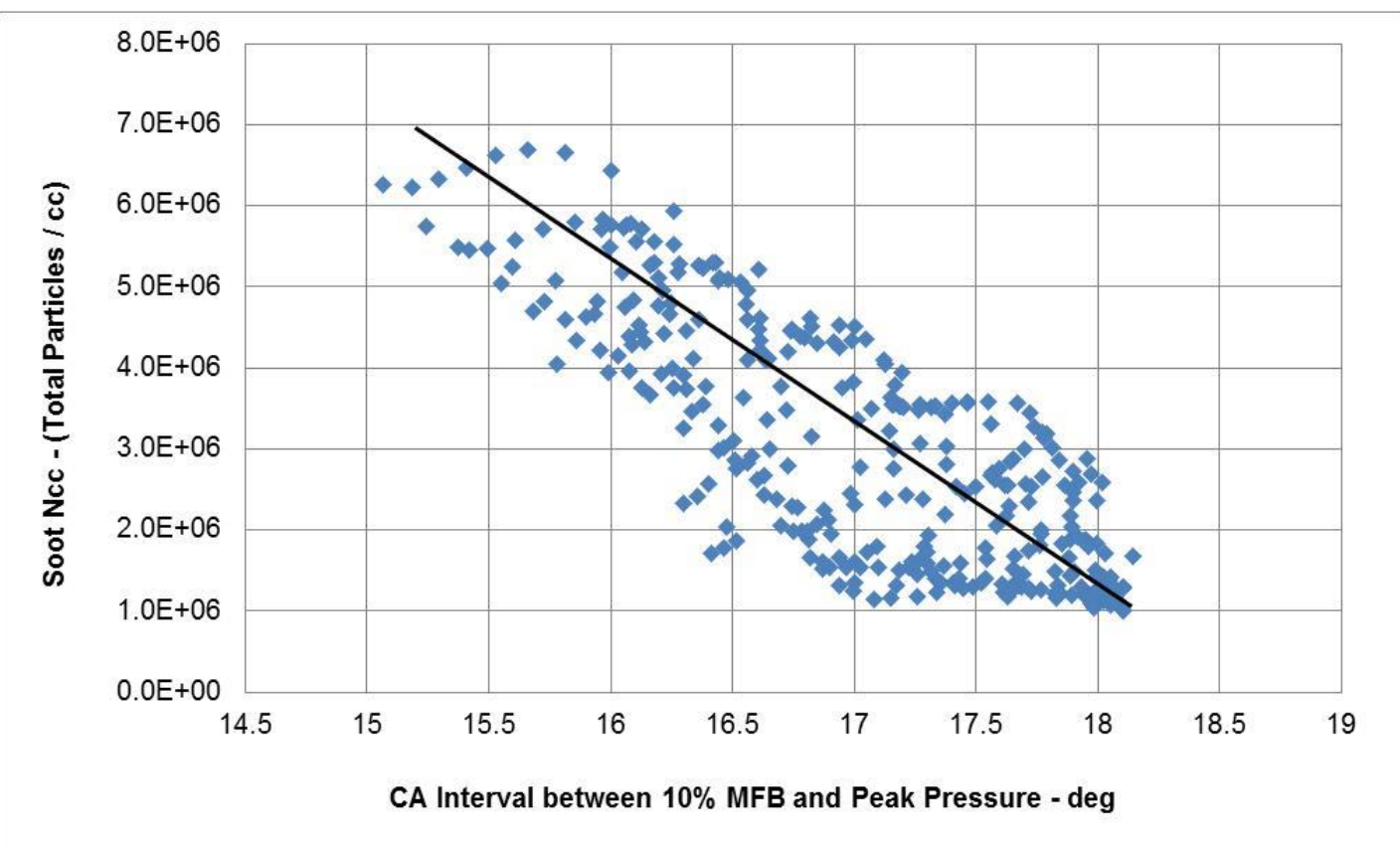

Figure 10. Correlation between exhaust soot number density and $\mathrm{RBP}_{\max }$. Points are derived by applying a classic $(20 \times 20)$ grids for the cubic interpolation of the two experimental quantities. 


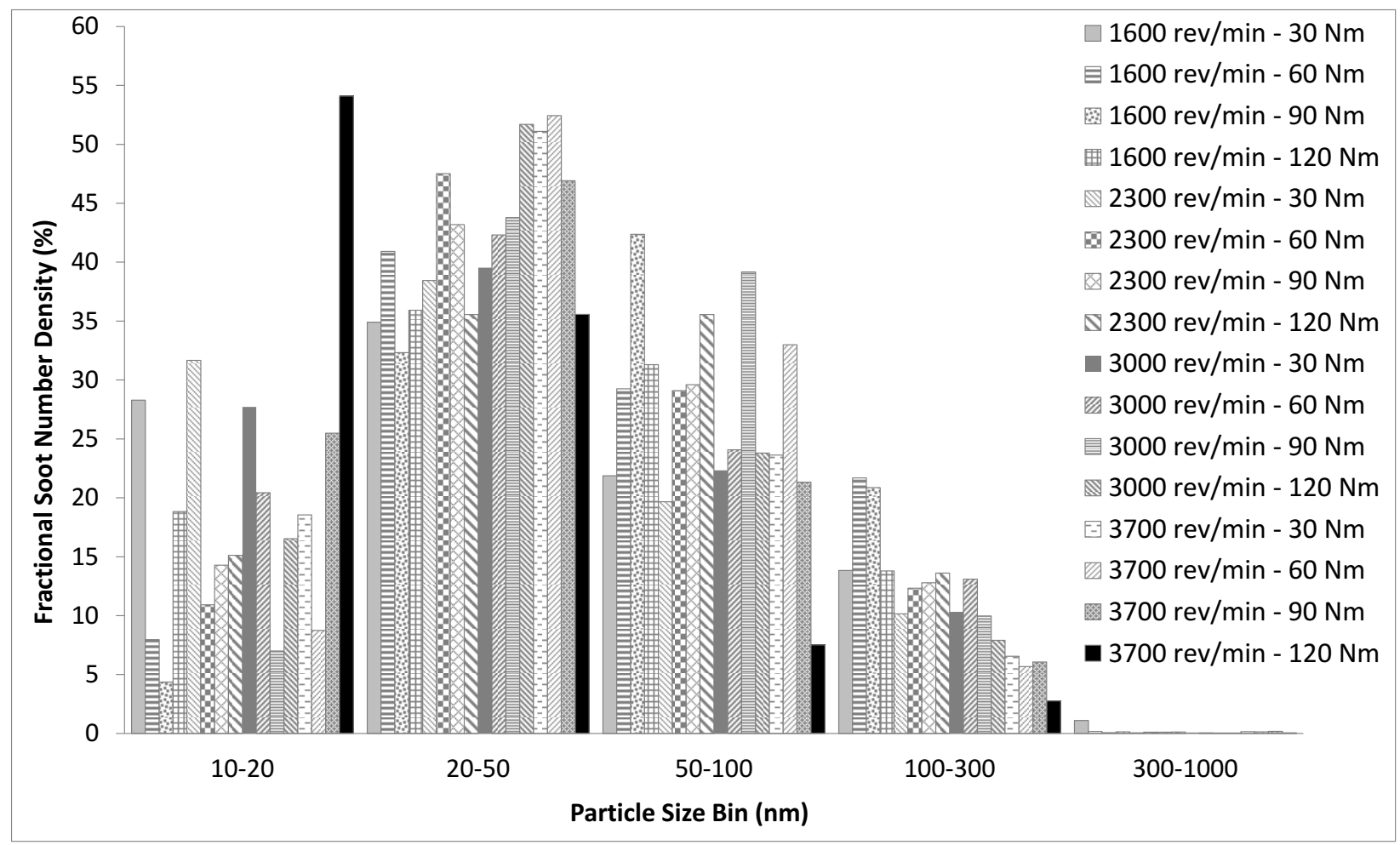

Figure 11. Fractional soot number density (\%), as a function of 5 particle size bins (particle diameter in $\mathrm{nm}$ ), for 16 engine running conditions. Measured particles with diameter smaller than $10 \mathrm{~nm}$ are excluded from the analysis.

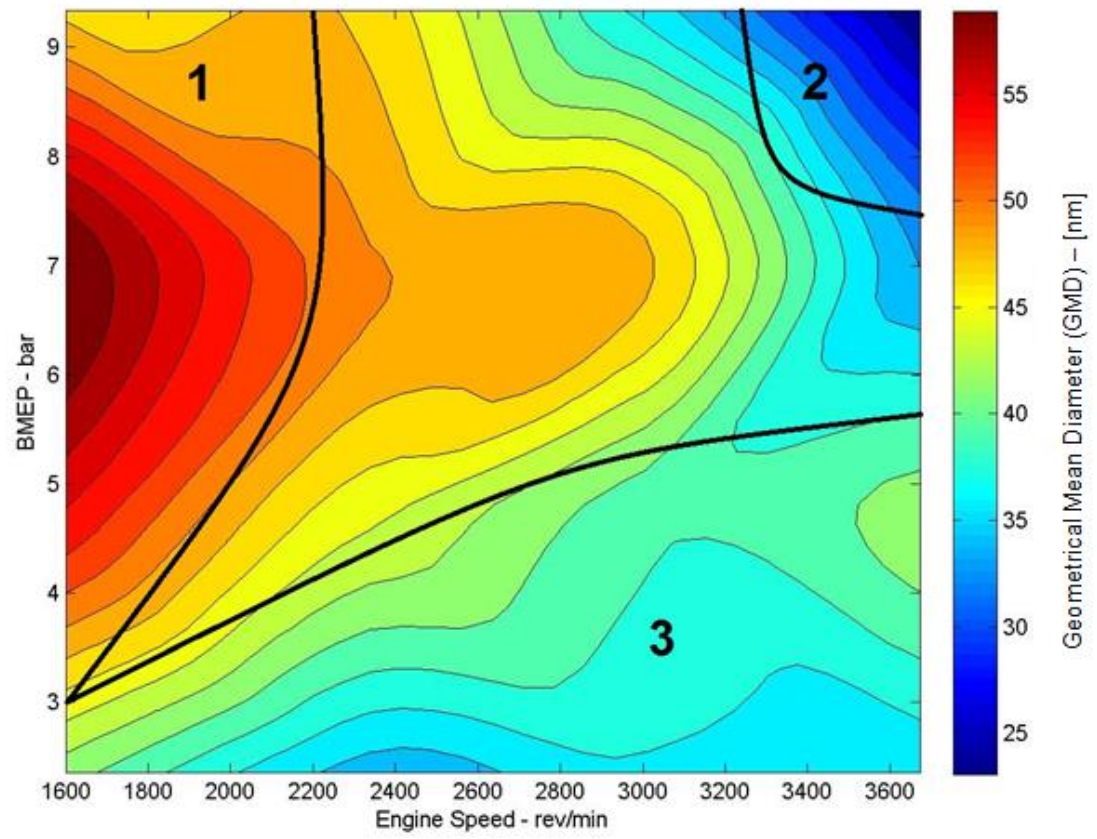

Figure 12. Experimental Soot Geometrical Mean Diameter (GMD), as a function of engine speed and load (BMEP). Measured particles with diameter smaller than $10 \mathrm{~nm}$ are excluded from the analysis. 


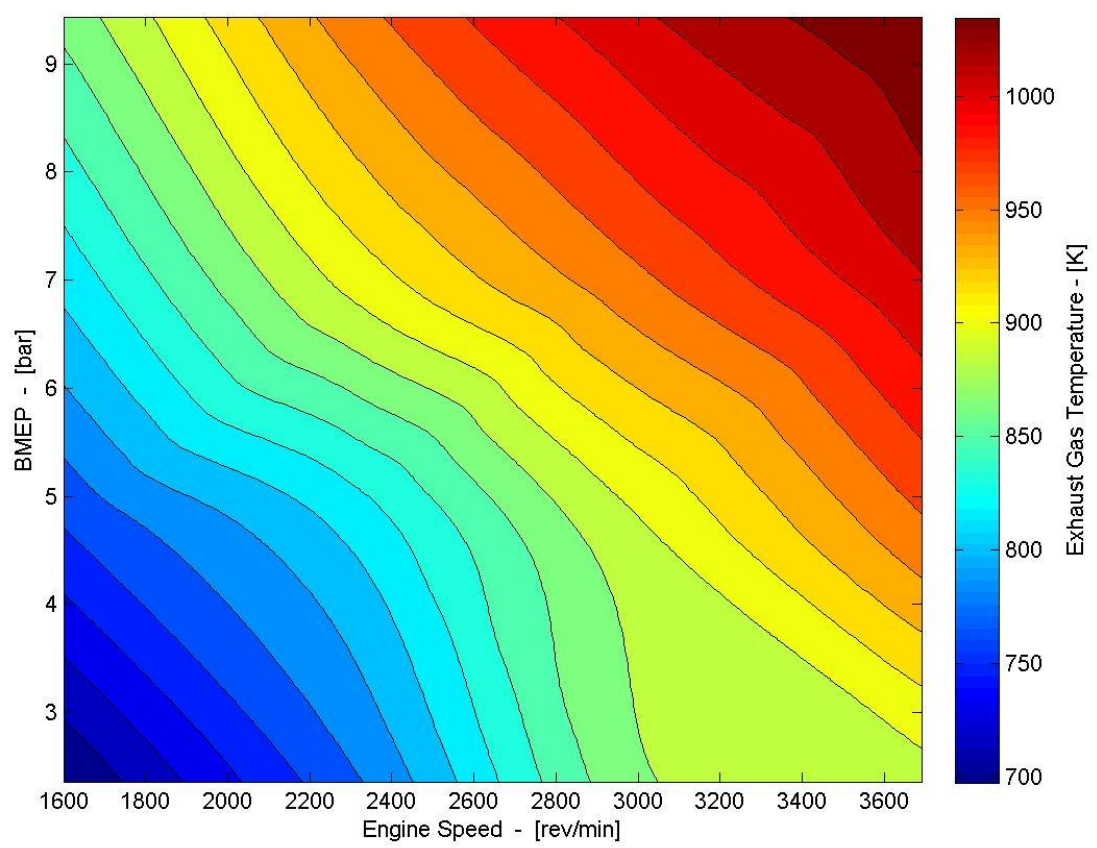

Figure 13. Measured exhaust gas temperature, as a function of engine speed and load (BMEP).

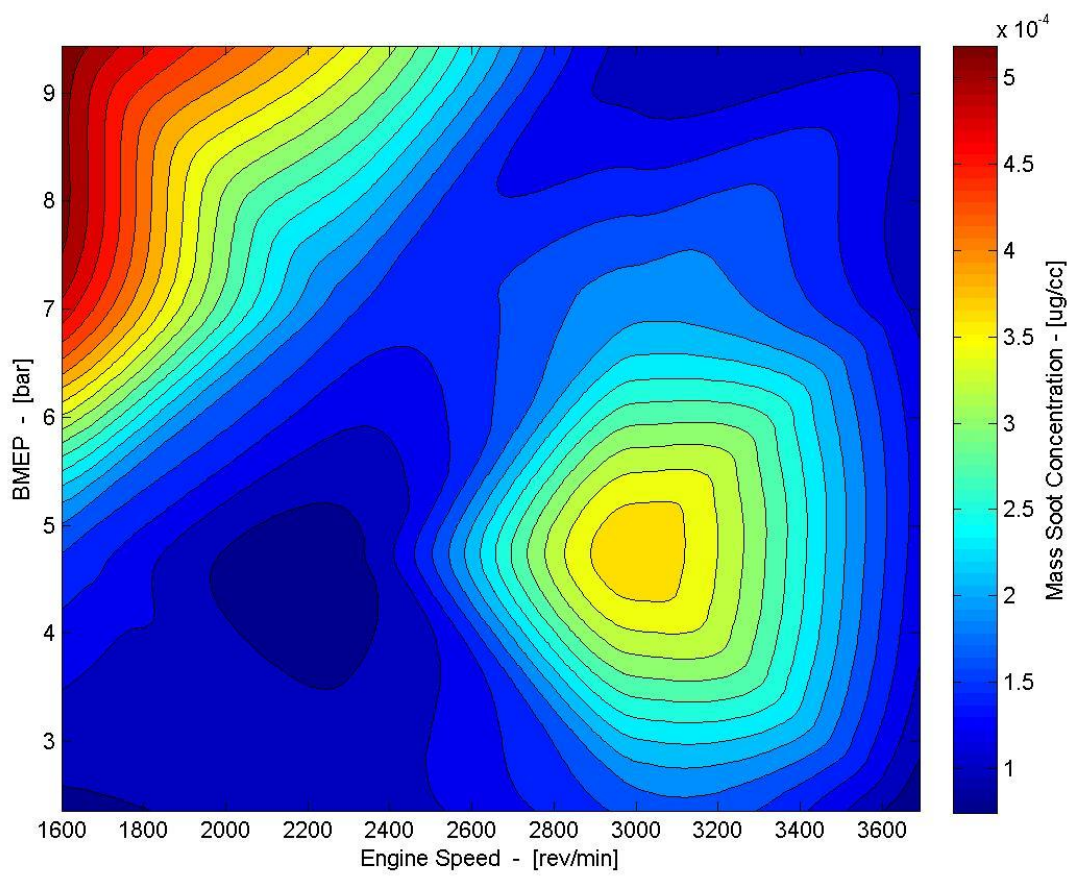

Figure 14. Computed soot mass concentration, as a function of engine speed and load (BMEP). Measured particles with diameter smaller than $10 \mathrm{~nm}$ are excluded from the analysis. 
Tables

806

\begin{tabular}{|l|l|}
\hline Displacement $\left(\mathrm{cm}^{3}\right)$ & 1598 \\
\hline Bore (mm) & 77 \\
\hline Compression ratio & $10.5: 1$ \\
\hline Connecting Rod Length (mm) & 138.4 \\
\hline Combustion Chamber & 4 -Valve, Central Spark Plug, Pent-Roof Design \\
\hline Engine type & In-line 4-cylinder \\
\hline Cycle & 4 -stroke Spark Ignition \\
\hline Fuel Injection system & Direct Injection Common Rail \\
\hline Fuel Injectors & Side-mounted, wall-guided spray \\
\hline Maximum Injection Pressure (bar) & 120 \\
\hline Maximum Engine Speed (rev/min) & 6000 \\
\hline Maximum Rated Torque (Nm) & 240 \\
\hline
\end{tabular}

Table 1. Test engine technical specifications 